\title{
MICROCRÉDITO PRODUTIVO NO BRASIL: HISTÓRICO RECENTE E CONDICIONANTES DE DESENVOLVIMENTO
}

\author{
PRODUCTIVE MICROCREDIT IN BRAZIL: RECENT HISTORY AND CONDITIONS OF DEVELOPMENT \\ MICROCRÉDITO PRODUCTIVO EN BRASIL: HISTORIA RECIENTE Y CONDICIONANTES DE DESARROLLO
}

\section{RESUMO}

0 artigo tem 0 objetivo de analisar os direcionadores para a atuação dos diferentes modelos institucionais do microcrédito produtivo no Brasil. Utiliza-se o modelo "multinível" a fim de investigar a relação entre os interesses e processos de negociação entre os grupos envolvidos no microcrédito. 0 estudo empírico inclui um banco público, uma Sociedade de Crédito ao Microempreendedor e à Empresa de Pequeno Porte (Scmepp), e uma Oscip de microcrédito. Os resultados mostram que o foco na gestão da implementação da metodologia do microcrédito produtivo orientado é condicionante para atingir bons resultados. Parcerias com órgãos governamentais, bem como a participação das instituições de microcrédito nos processos de políticas públicas, são um grande desafio e potencial para 0 aprimoramento do setor de microcrédito.

PALAVRAS-CHAVE: Microfinanças, microcrédito produtivo, modelos de atuação, processos de negociação, condicionantes de desenvolvimento.

Lauro Gonzalez lauro.gonzalez@fgv.br

Professor da Fundação Getulio Vargas, Escola de Administração de Empresas de São Paulo - São Paulo - SP, Brasil

Lya Porto lyaporto2@gmail.com

Doutora em Administração Pública e Governo pela Fundação Getulio Vargas, Escola de Administração de Empresas de São Paulo - São Paulo - SP, Brasil

Eduardo Henrique Diniz eduardo.diniz@fgv.br

Professor da Fundação Getulio Vargas, Escola de Administração de Empresas de São Paulo - São Paulo - SP, Brasil

Submetido 25.06.2016. Aprovado 07.08.2017

Avaliado pelo processo de double blind review.

DOI: http://dx.doi.org/10.12660/cgpc.v22n72.62637 


\section{Abstract}

This article aims to analyze the elements determining the action of different institutional models of productive microcredit. We used a multilevel model to investigate the relationship between interests and negotiation processes among groups involved in microcredit. The empirical study was conducted with three units of analysis: a public bank, a company the provides credit for micro entrepreneurs and small businesses (SCMPP), and a civil society organization of public interest (OSCIP) operating in microcredit. Results show that focus on managing the implementation of the Oriented Productive Microcredit methodology is a condition to achieve good results. Partnerships with government agencies, as well as the participation of microfinance institutions in public policy processes, are a major challenge and a major potential to enhancing the microcredit sector.

Keywords: Microfinance, productive microcredit, negotiation processes, conditions of development.

\section{Resumen}

El artículo tiene como objetivo analizar las directrices para la actuación de los diferentes modelos institucionales del Microcrédito Productivo en Brasil. Se utiliza el modelo "multinivel" para investigar la relación entre los intereses y procesos de negociación entre los grupos involucrados en el microcrédito. El estudio empírico se llevó a cabo utilizando tres unidades de análisis: un banco público, una Sociedad de Crédito al Microemprendedor y a Pequeñas Empresas y una Organización de la Sociedad Civil de Interés Público. Los resultados muestran que el enfoque en la gestión de la implementación de la metodología de Microcrédito Productivo Orientado es un condicionante para lograr buenos resultados. Las alianzas con organismos gubernamentales, as í como la participación de las instituciones de microfinanzas en los procesos de políticas públicas son un gran desafío y potencial para el mejoramiento de este campo.

Palabras Clave: Microfinanzas, Microcrédito Productivo, Modelos de Actuación, Procesos de Negociación, Condicionantes de Desarrollo.

\section{INTRODUÇÃO}

O microcrédito surgiu como uma "promessa" de inclusão social por meio de empréstimos e financiamentos direcionados para atividades geradoras de renda (Morduch, 1999), tais como pequenos comércios e manufaturas nas periferias das regiões urbanas. As últimas décadas se caracterizaram por elevada expansão de ativos financeiros vis-à-vis o lado real da economia. Conforme Wolf (2007), a proporção entre ativos financeiros e o PIB mundial era aproximadamente um para um, no início da década de 1980. Já em 2007, para cada dólar de PIB mundial, havia cerca de quatro dólares de ativos financeiros.

No caso brasileiro, estimativas baseadas no Global Entrepreneurship Monitor (GEM) (2014) mostram que o País possui 45 milhões de empreendedores, a maioria informais, aptos a participar do mercado de crédito. Desse número, pouco mais de dois milhões são atualmente atendidos, mostrando que, também aqui no Brasil, prevalece uma situação de desigualdade no acesso aos serviços financeiros.

A evolução do microcrédito no Brasil foi fortemente condicionada pela atuação do setor público, com destaque para a atuação do Banco do Nordeste por meio do Programa Crediamigo, maior iniciativa do segmento no País.

O setor privado, apesar de iniciativas relevantes, como a empreendida pela Real Micro- 
crédito (Gonzalez, Diniz, \& Pozzebon, 2015), tem desempenhado papel menor e predominantemente reativo às iniciativas do setor público. Interessante notar que a relevância da atuação do setor público torna o Brasil uma exceção importante quando comparado a outros países, uma vez que o microcrédito tem sido utilizado e propagado como uma solução "de mercado" para o combate à pobreza (Khavul, 2010). Portanto, a dinâmica da evolução do microcrédito no Brasil é distinta e pouco analisada.

Os trabalhos publicados sobre o tema não analisam aspectos relacionados aos diversos atores envolvidos e que acabaram por condicionar a evolução histórica do microcrédito (Cacciamali, Matos, \& Macambira, 2014; Neri \& Giovanini, 2005; Zouain \& Barone, 2007). Assim, este artigo apresenta uma análise baseada na identificação desses atores, seus interesses, processos de negociação e modelos efetivamente postos em prática. $O$ objetivo principal é analisar os direcionadores para a atuação dos diferentes modelos institucionais do microcrédito produtivo no Brasil.

Para atingir esse objetivo, foram selecionados para a análise três tipos distintos de instituições atuantes no microcrédito: um banco público de desenvolvimento regional - Banco do Nordeste, uma empresa privada - a Empresta Capital, e uma organização sem finalidade de lucro, o Banco Pérola. Essas organizações representam os três formatos legais mais representativos na atuação no microcrédito: Organizações da Sociedade Civil de Interesse Público (Oscips), Sociedade de Crédito ao Microempreendedor e ao Empreendedor de Pequeno Porte (Scmepp) e bancos públicos. As Oscips não têm fina- lidade de lucro, sendo registradas e reguladas pelo Ministério da Justiça. Já as Scmepp visam lucro e dependem de autorização do Banco Central para o devido funcionamento. Do ponto de vista conceitual, utiliza-se o modelo "multinível", que permite analisar a relação entre resultados e processos de negociação dos grupos sociais relevantes. A análise da dimensão processo será realizada em três níveis de atuação - micro, meso e macro (Helms, 2006).

O artigo está dividido em três seções principais. A primeira traz uma revisão da literatura sobre o tema, incluindo a apresentação dos diferentes modelos institucionais de microcrédito, seus métodos, inovações, e evolução histórica. A segunda é a apresentação do modelo conceitual e da metodologia. Finalmente, na terceira seção, aplica-se o modelo conceitual para a análise dos casos propostos.

\section{REVISÃO DA LITERATURA}

O estudo das microfinanças tem gerado importantes contribuições teóricas e empíricas que examinam as razões pelas quais o sistema financeiro tradicional é pouco eficiente no que diz respeito à inclusão dos pobres. Baseado em Lavoie, Pozzebon e Gonzalez (2011), o termo microfinanças pode ser definido como a provisão de serviços financeiros para população de baixa renda, excluída do sistema financeiro tradicional, por meio de uma metodologia diferenciada.

A definição acima permite uma visão abrangente do microcrédito, incluindo diversas modalidades de crédito para consumo. Entretanto, o presente trabalho tem como foco o microcrédito produtivo, destinado exclu- 
sivamente ao financiamento de atividades produtivas. Doravante, o emprego do termo microcrédito passa a ser utilizado unicamente para denotar o microcrédito produtivo.

Morduch (1999), Roodman e Morduch (2014) abordam o microcrédito a partir das lentes da teoria da informação assimétrica e dos custos de transação. Tal abordagem salienta os "obstáculos" que impediriam o funcionamento de um modelo típico de mercado perfeito, no qual o capital fluiria naturalmente rumo aos mais pobres em busca de retornos marginais superiores.

Aghion e Morduch (2010) definem três obstáculos que impedem o direcionamento do capital à população de mais baixa renda. $\mathrm{O}$ primeiro deles é a falta de informação, ou seja, não há um histórico sobre o comportamento financeiro dos pobres, simplesmente pelo fato de estes estarem excluídos do sistema financeiro tradicional. O segundo obstáculo é a ausência de colaterais ou garantias que poderiam ser utilizadas para mitigar a falta de informação. Obviamente, os pobres não têm ativos tradicionais que possam ser oferecidos como garantia. O terceiro obstáculo é o custo de transação. Por se tratar de serviços financeiros para população de baixa renda, os volumes das operações são baixos, encarecendo os custos associados aos serviços.

O que atualmente se denomina microfinanças surge a partir de soluções e práticas inovadoras que superem os obstáculos dos problemas informacionais e reduzam os custos de transação. Segundo Gonzalez, Piza e Garcia (2009), é possível afirmar que as diversas experiências de microfinanças no mundo tendem a combinar um conjunto de inovações que ganharam grande repercussão, com o Grameen, em Bangladesh, e seu programa de microcrédito.

Segundo Morduch (1999), as principais inovações do microcrédito são os empréstimos em grupo e o uso de agentes de crédito. Os primeiros podem ser definidos como arranjos feitos por indivíduos que não dispõem de garantias tradicionalmente demandadas pelo sistema bancário. Essas pessoas formam espontaneamente um grupo cujo objetivo é a obtenção de empréstimos. Cada membro do grupo recebe determinado valor e, simultaneamente, garante os empréstimos dos demais. Portanto, em caso de inadimplência de um dos membros, os demais devem pagar a parcela correspondente, sob pena de não receberem mais créditos. A grande vantagem do empréstimo em grupo é lidar com o problema da assimetria de informação e dos elevados custos de transação.

Há evidências de que os arranjos formais em grupo são capazes de obter e utilizar as informações locais de maneira semelhante aos credores in-formais. Al-Azzam, Carter e Sudipta (2012) fizeram uma revisão sobre os estudos empíricos relacionados aos empréstimos em grupo das instituições de microfinanças e ressaltaram os efeitos positivos desse tipo de arranjo para a redução de inadimplência. Os grupos permitem seleção, monitoramento e controle coletivo, o que proporciona aumento das taxas esperadas de repagamento.

A segunda inovação é a utilização do chamado agente de crédito, que é o profissional responsável pelo levantamento de dados sobre tomadores, principalmente novos empreendedores ou grupos, acompanhamento 
e auxílio a clientes, emissão e análise de relatórios técnicos e recuperação de crédito de tomadores inadimplentes. O agente de crédito é o principal responsável pela inserção do microcrédito em uma determinada comunidade e, conforme Quayes (2012), tem papel importante para que o crédito alcance os mais pobres.

No Brasil, a primeira iniciativa de microcrédito ocorreu na década de 1970, e, desde então, essa área foi caracterizada por diferentes quadros institucionais classificados em quatro momentos principais (Monzoni, 2006). O primeiro momento histórico foi marcado pela articulação das instituições de microfinanças nacionais às redes internacionais como o Banco da Mulher - Associação Brasileira para o Desenvolvimento da MuIher e o Sistema Centro de Apoio aos Pequenos Empreendimentos (Ceape). Nesse momento, as organizações de microcrédito nacionais incorporaram bases metodológicas e técnicas dos órgãos internacionais $\mathrm{e}$ contribuíram para a formação de agentes de crédito com especialidade no mercado informal.

O segundo momento histórico das microfinanças ocorreu nas décadas de 1980 e 1990, e se caracterizou pela entrada das organizações da sociedade civil. No terceiro momento, no final da década de 1990 e início dos anos 2000, o grande marco foi a entrada e atuação de instituições governamentais, principalmente das esferas estaduais e municipais. Nesse momento foram criados os Bancos do Povo e o Crediamigo, maior programa de microcrédito brasileiro, fundado em 1998 e vinculado ao Banco do Nordeste, oficialmente um banco de desenvolvimento regional (Monzoni, 2006).
No quarto momento, ocorreu a entrada do setor privado a partir da promulgação da Lei n. 10.194/01, que autoriza a instituição de Sociedades de Crédito ao Microempreendedor (SCM), posteriormente transformada em Scmepp. Essas instituições, ao contrário das Oscips, podem obter lucro e têm o objetivo de expandir seu serviço às empresas de pequeno porte e conceder crédito a clientes que não possuem garantias exigidas pelos bancos tradicionais.

Embora Monzoni (2006) descreva apenas os quatro momentos anteriores, a dinâmica do microcrédito permite falar em um quinto momento, atualmente em vigor, que se define por meio do fortalecimento de políticas públicas voltadas para o microcrédito, cujo marco inicial foi a criação do Programa Nacional de Microcrédito Produtivo Orientado (PNMPO) em 2005, coordenado pelo Comitê Interministerial formado pelo Ministério do Trabalho e Emprego, Ministério da Fazenda e Ministério do Desenvolvimento Social e Combate à Fome.

Em suma, esses cinco momentos históricos permitem compreender a entrada dos diferentes tipos de instituições no segmento do microcrédito - organizações internacionais, da sociedade civil, do setor público e do setor privado. Importante diferenciar que, no terceiro momento, a entrada do Estado ocorreu por meio dos bancos públicos, e, no quinto momento, a entrada do setor público se consolidou a partir das políticas públicas de microcrédito.

Tendo em vista esse quadro histórico, é preciso analisar as diferenças nos ambientes institucionais dos serviços de microcrédito, nos processos de negociação e nos resulta- 
dos de cada setor organizacional. Ademais, é necessário identificar as inter-relações entre essas diferentes instituições. Portanto, essa dinâmica organizacional será aprofundada pela análise apresentada nesse artigo.

\section{MODELO CONCEITUAL E MÉTODO}

O modelo conceitual adotado neste trabaIho é baseado em Pozzebon, Diniz e Jayo (2008), que propõem um modelo "multinível" utilizado por várias pesquisas em microfinanças no Brasil (Cernev, 2010; Diniz, Pozzebon, \& Jayo, 2009; Jayo, 2010). Fundamentalmente, o modelo captura a ideia de que o microcrédito e a sua evolução foram e são influenciados por interesses e valores moldados pelas inter-relações entre indivíduos, grupos, organizações e redes.

O modelo "multinível" é baseado na combinação de três vertentes teóricas: estruturação, moldagem social da tecnologia (Social Shaping Technology) e contextualismo. É importante ressaltar que, embora o modelo tenha sido desenvolvido para a análise do uso e dos efeitos de tecnologias na sociedade e nas instituições, a tecnologia diz respeito ao objeto de uso ou da materialidade em questão. Nesse sentido, a materialidade analisada na presente pesquisa é o microcrédito. Portanto, o que se refere à tecnologia está sendo transposto para o microcrédito.

A teoria da estruturação é proposta por Anthony Giddens e sugere um entrelaçamento da relação entre estrutura e agência (Pozzebon et al., 2008). Ao transpor essa ideia para o microcrédito, observa-se como a estrutura institucional influencia a ação humana perante o microcrédito e vice-versa. A teoria da moldagem social da tecnologia é fortemente influenciada pelas teorias sociais do construtivismo e atenta para a diversidade de sentidos atribuídos ao objeto de negociação, neste caso, o microcrédito. A abordagem contextualista propõe três dimensões para a análise das transformações nas organizações: contexto, processo e conteúdo.

Importante ressaltar que, no modelo "multinível," as três dimensões acima (contextualismo) são articuladas com a ideia das duas teorias anteriores, que partem do pressuposto da existência de uma mútua influencia entre instituições e agência (teoria da estruturação) a partir dos sentidos atribuídos ao objeto de negociação, o microcrédito (teoria da moldagem social). Com isso, a aplicação do modelo "multinível" ao microcrédito se dará a partir de uma análise sobre a mútua influência entre ações e estruturas institucionais nas dimensões contexto, processo e conteúdo.

Os principais aspectos a serem analisados no fenômeno do microcrédito são os seguintes: (1) dimensão contexto: caracterização dos quadros interpretativos dominantes que determinam a percepção e sentidos atribuídos ao microcrédito para cada um dos grupos envolvidos (banco público, Scmepp, Oscip); (2) dimensão processo: análise dos meios pelos quais os diferentes grupos, a partir de seus interesses e valores, exercem influência sobre a implementação do microcrédito; (3) dimensão conteúdo: conclusões ou considerações sobre as resultantes do microcrédito na prática, com base no que efetivamente se observa na implementação, a partir do processo de negociação e visão dos distintos grupos envolvidos. 
Essas dimensões são formadas por meio de quatro conceitos principais: (1) frames tecnológicos, (2) grupos sociais relevantes, (3) processo de negociação e (4) tecnologia em prática. Os frames tecnológicos são os interesses, suposições ou expectativas formadas pelos indivíduos em relação ao Microcrédito Produtivo (MP). Os grupos sociais relevantes são os indivíduos que tendem a compartilhar os mesmos frames tecnológicos. O processo de negociação captura os meios pelos quais os diferentes grupos, a partir de seus interesses e valores, exercem influência sobre a implementação do MP. Por fim, a tecnologia em prática é o resultado da negociação em torno do MP. Uma descrição mais detalhada desses quatro conceitos pode ser encontrada em Lavoie, Pozzebon e Gonzalez (2011).

O método adotado para a pesquisa é o estudo de casos múltiplos (Yin, 2001), com o objetivo de analisar o fenômeno das ações institucionais no campo do microcrédito em três unidades de análise diferentes: Banco do Nordeste do Brasil (banco público), Empresta Capital (Scmepp) e Banco Pérola (Oscip). A escolha dessas unidades pode ser mais bem compreendida à luz do processo histórico do microcrédito no Brasil, anteriormente apresentado, de onde se depreende que emergiram dois tipos institucionais especificamente voltados ao microcrédito: instituições sem fins lucrativos (Oscips) e com fins lucrativos (Scmepp).

Ademais, na evolução do caso, anteriormente descrita, evidencia-se a importância das iniciativas públicas, em particular o papel pioneiro do Banco do Nordeste. Os três tipos de instituição aqui abordados são res- ponsáveis por quase $90 \%$ da oferta de microcrédito no Brasil. Portanto, adotou-se o critério de relevância para escolher os tipos institucionais mencionados. Por fim, a escoIha dos atores específicos para cada um dos três tipos institucionais baseou-se no destaque de atuação institucional dentro do seu segmento e disponibilidade de colaboração e viabilidade de pesquisa de campo.

De fato, o Banco do Nordeste detém cerca de $80 \%$ de microcrédito de sua área de atuação (IPEA, 2010) e oferta o maior programa de microcrédito da América do Sul (BNB, 2017). A Empresta Capital é uma das maiores Scmepps e sempre exerceu papel de destaque e liderança no seu meio, sendo que o dirigente entrevistado e atual presidente da Associação das Scmepps representa um importante interlocutor quando se almeja capturar os interesses das Scmepp. Finalmente, o Banco Pérola também tem recebido destaque significativo entre as Oscips de microcrédito, sobretudo pela busca da inovação, exemplificada na prática pelo foco em negócios recém-iniciados, e geralmente negligenciados pelas demais Oscips, que demandam ao menos um ano de existência dos empreendimentos.

A coleta de dados e informações foi realizada mediante a análise de documentos - relatórios publicados pelas organizações investigadas e entrevistas semiestruturadas com dois dirigentes do Banco do Nordeste, um da Empresta Capital e dois do Banco Pérola.

\section{ANÁLISE EMPÍRICA DAS INSTITUIÇÕES DE MICROCRÉDITO}

Grupos sociais e instituições envolvidos nos 
processos de inclusão financeira.

A consolidação do acesso ao crédito pela população de baixa renda depende da integração dos serviços financeiros em três níveis de atuação: micro, meso e macro (Hel- ms, 2006). De acordo com essa concepção, os tomadores de crédito estão no centro do sistema financeiro, pois suas demandas determinam e influenciam as ações dos grupos e instituições inseridos nos outros níveis.

Figura1. Instituições e grupos envolvidos nos processos de inclusão financeira no Brasil

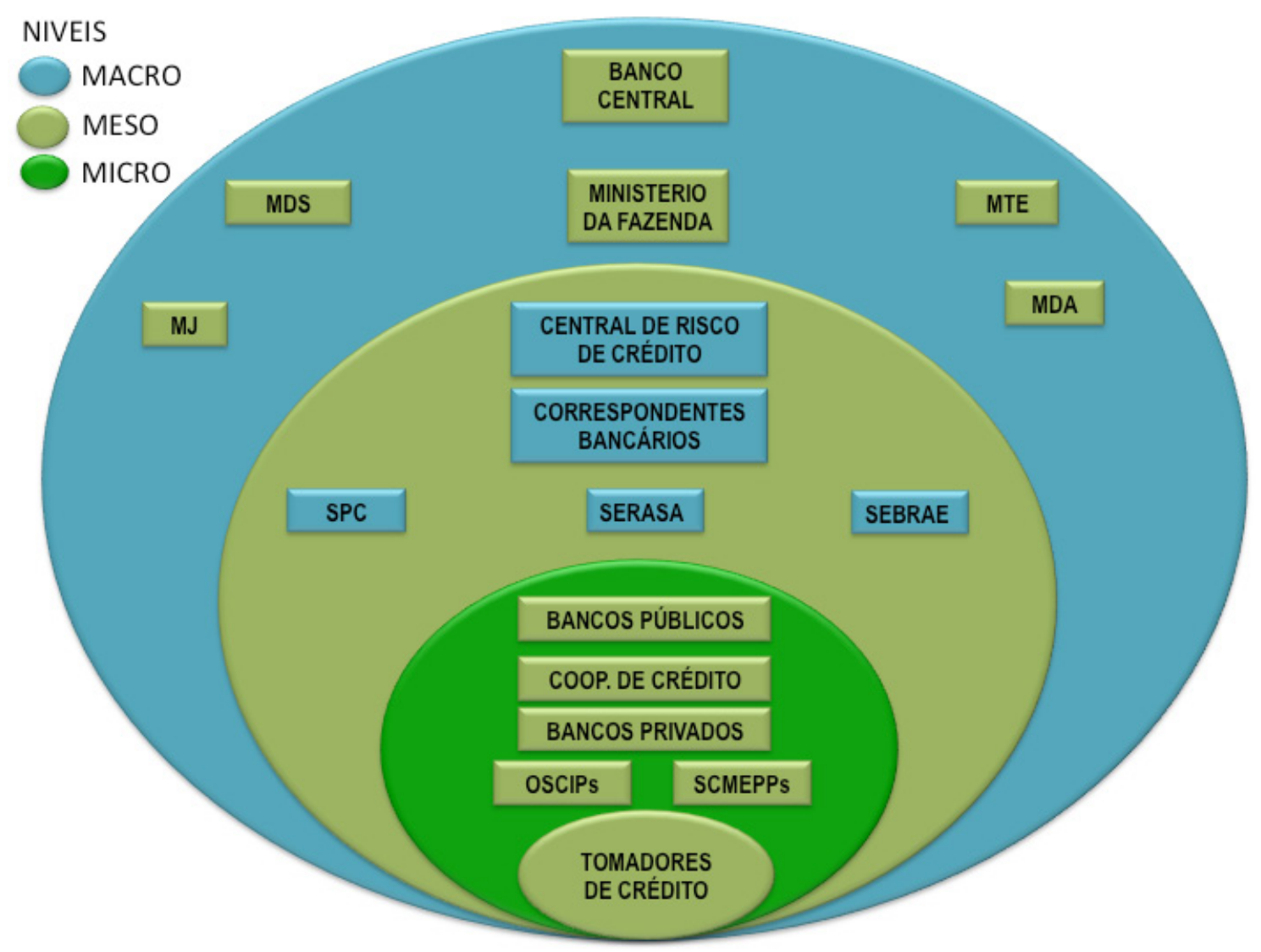

O nível micro é constituído por instituições que estão em contato direto com os clientes ou usuários. No caso brasileiro, fazem parte desse nível os bancos públicos e comerciais, as cooperativas de crédito, as Scmepps, assim como as Oscips.

O nível meso é formado por instituições ligadas à infraestrutura do sistema financeiro, responsáveis por soluções tecnológicas, logísticas, de risco, entre outras. Sua atu- ação reduz custos de transação e promove transparência dos serviços. No Brasil, é possível citar o Sebrae, instituição de apoio e provedora de serviços de treinamento, ou ainda a Serasa e a Boa Vista, birôs de crédito responsáveis pelo compartilhamento de informação.

O nível macro é composto essencialmente pela estrutura regulatória, de maneira a afetar os atores dos níveis meso e micro. Assim, 
o Banco Central é a instituição-chave, mas, no Brasil, diversos ministérios e outros órgãos governamentais estão envolvidos nas políticas de microcrédito, como ressaltado na figura acima.

Cumpre lembrar que os grupos sociais estão em constante negociação, e as inter-relações ocorrem tanto no mesmo nível como entre diferentes níveis. Todavia, as relações não são simétricas e neutras, e existem diferenças de capacidade de articulação política entre os atores, assimetrias de poder entre eles, e, no caso de instituições governamentais, momentos de abertura e fechamento político.

\section{Banco público - Banco do Nordeste}

\section{Dimensão contexto}

O Banco do Nordeste foi fundado em 1954 com o objetivo de atuar na concessão de financiamentos para a agricultura, e, na década de 1990, ele voltou-se para o financiamento de micro e pequenos negócios. Em 1998, foi criado o programa Crediamigo, direcionado para a população urbana, e hoje representa o maior ator de MP no País, com uma carteira de praticamente 2,1 miIhões de clientes ativos (Banco do Nordeste, 2016). Em 2005, foi criado o Agroamigo, voltado para o MP rural. Na prática, o Agroamigo atende hoje 1,5 milhão de agricultores familiares, quase todos cadastrados no Pronaf (Banco do Nordeste, 2016).

No ano de 2012, o Banco do Nordeste passou por uma reestruturação, e os programas Crediamigo e Agroamigo passaram a ter uma única gestão. Segundo o novo su- perintendente:

O Crediamigo sempre foi muito forte em resultado, só que eu trouxe outra mensagem. Resultado não é só resultado de operações, de contratação. $O$ resultado, ele é maior. Resultado é evitar perdas operacionais, ele é mais pró-ativo. Ter controle é ter coordenação de processo, e ter processo mais enxuto em geral. (entrevista com superintendente do Banco do Nordeste, novembro de 2013)

Diante da perspectiva do superintendente do Banco do Nordeste, os principais destaques da atuação do banco são o foco na gestão para resultados e a adoção do método do Microcrédito Produtivo Orientado (MPO), em que os agentes de crédito fazem um acompanhamento da gestão dos microempreendedores, tomadores de crédito. No caso do Agroamigo, os agentes têm formação técnica na área agropecuária, o que Ihes permite realizar um acompanhamento mais direcionado à realidade das atividades agrícolas. Segundo o coordenador do Banco do Nordeste, em outros países, muitos concessores de crédito rural financiam a coIheita, o capital de giro, e não reconhecem a dinâmica dos negócios rurais, sujeitos aos riscos de perda por adversidades, como o clima. A dinâmica da implementação do crédito rural é muito mais complexa e arriscada. Nas palavras do superintendente do Banco do Nordeste:

Uma coisa é eu comprar cerveja hoje para vender à noite. Pode chover que eu vendo a cerveja. Outra coisa é eu financiar uma operação de dois anos num estado, numa região que a cada 8,10 anos, nós temos 6 anos na baixa estação. (entrevista com 
superintendente do Banco do Nordeste, novembro de 2013)

Diante da complexidade das atividades produtivas, o agente de crédito possui um papel fundamental para a orientação do planejamento financeiro de seus clientes, tanto no meio rural, por meio do Agroamigo, como no meio urbano, por meio do Crediamigo.

O Banco do Nordeste destaca-se pela realização de parcerias com organizações de diferentes níveis de atuação: micro, meso e macro, como abordado a seguir.

\section{Dimensão processo}

Os processos de negociação e articulação do Banco do Nordeste com outras instituições se dão em todos os níveis: micro, meso e macro. No nível micro, o banco tem parcerias com duas Oscips: o Instituto Nordeste de Cidadania e o Vivacred. "E trabalhar com Oscip é fundamental, não dá para trabalhar esses dois programas com funcionário do banco, não tem porquê, não dá viabilidade econômica", afirma o superintendente do Banco do Nordeste. Para admitir um funcionário via Banco do Nordeste, é necessária a realização de concurso público, o que torna a contratação de pessoal muito burocrática.

O termo de parceria entre o banco e a Oscip é assinado a cada dois anos, e as responsabilidades de cada ente são claras e definidas. A operação, a metodologia, as estratégias, a política e os manuais são do Banco do Nordeste, e a Oscip é responsável pela operacionalização desses processos por meio do cumprimento de regras e metas. Ainda no nível meso, o Banco do Nordeste tem uma parceria com a Mapfre Seguros, na modalidade de seguro prestamista, atrelada às operações de microcrédito.

No nível macro, o banco possui parcerias com diversos ministérios e com o Banco Central. Uma das estratégias fundamentais do Agroamigo é a parceria estabelecida com o Ministério do Desenvolvimento Agrário (MDA), pois, segundo o superintendente do Banco do Nordeste, no meio rural, é necessário criar uma cadeia de programas governamentais para reduzir os riscos, que estão relacionados principalmente ao preço, clima e comercialização. O Banco do Nordeste também auxilia seus clientes a acessarem políticas públicas como o Programa Garantia de Preço, AgroMais, Programa de Aquisição de Alimentos, Programa Nacional de Alimentação Escolar e Zoneamento Agrícola da Embrapa.

O Banco do Nordeste também tem parceria com o Ministério do Desenvolvimento Social (MDS). Trata-se de uma cooperação tanto do Crediamigo quanto do Agroamigo com o Programa Bolsa Família (PBF). "Isso é muito bom, porque hoje, no Agroamigo, do total de nossa carteira ativa, dos 800 mil clientes, $60 \%$ têm Bolsa Família. Estamos falando de 480 mil [pessoas]." O superintendente do Banco do Nordeste também afirmou que, no caso do Crediamigo, $42 \%$ de seus clientes são beneficiários do PBF (entrevista com superintendente do Banco do Nordeste, novembro de 2013). Portanto, mais de um miIhão dos clientes do Banco do Nordeste são beneficiários do PBF. Por meio desse convênio, o banco pode acessar a base de dados do PBF para conhecer o perfil do cliente e beneficiário do programa, além de estabelecer uma articulação entre a gerência local do Agroamigo ou Crediamigo e a gerência do 
PBF.

No que tange à participação política, há um grupo de discussão no MDA que se reúne mensalmente, e, por meio do diálogo com outros ministérios, instituições e movimentos sociais fazem propostas para regulamentações e políticas públicas. No caso do Crediamigo, há também um grupo similar no âmbito da Casa Civil e do Ministério da Fazenda que tratam do Programa Crescer, e outro grupo no Ministério do Trabalho para discutir o PNMPO. O superintendente do Banco do Nordeste alegou que muitas propostas do banco são acolhidas, transformando-se em regulamentação ou modificações nos programas de governo.

\section{Dimensão conteúdo}

Atualmente, considerando a Resolução $n$. 2.682, o Banco do Nordeste tem uma taxa de inadimplência de 1,2\%, Ao analisar o equilíbrio entre demanda e oferta de microcrédito, o entrevistado alegou que a demanda é geralmente mais alta do que a oferta, Mas, com a velocidade de crescimento de oferta do Banco do Nordeste, foi possível atender toda a demanda em alguns municípios menores.

Em 1999, foi proposto ao Banco do Nordeste o desafio do Agroamigo atender agricultores do grupo $B$, que estavam abaixo da linha da pobreza com um rendimento de até 4 mil reais por ano, e que não tinham acesso ao crédito bancário. $O$ Banco do Nordeste foi o primeiro banco a trabalhar com esse público. Todavia, como não havia acompanhamento adequado, a inadimplência do Banco do Nordeste chegou a $40 \%$, e hoje, mesmo após a pior seca dos últimos 50 anos, a inadimplência está em torno de $2 \%$. Essa mudança ocorreu após a implementação do método do microcrédito orientado.

Os resultados do Banco do Nordeste são fortemente marcados por três questões principais: (i) foco na gestão e nos resultados, (2) aplicação da metodologia de MPO, e (3) forte articulação com os programas de governo, bem como influência no processo decisório das políticas públicas e regulamentações do microcrédito.

Apesar de seus resultados positivos, a atuação do banco está articulada a um contexto maior, que envolve condições estruturais e econômicas do País. Nesse sentido, o superintendente do Banco do Nordeste acredita que o principal desafio é o avanço das tecnologias para a gestão, em geral, e para os meios de pagamento, em específico. Segundo o entrevistado, quando comparado aos outros países da América Latina, o Brasil é aquele que está menos avançado em termos de tecnologia para o microcrédito. Ademais, a dificuldade de acesso à internet em muitas regiões também prejudica esse avanço. E a deficiência na tecnologia impacta os custos operacionais.

No contexto mais amplo, outro desafio para o futuro do microcrédito é a implantação de um controle de sobre-endividamento. No Programa Crescer, por exemplo, existe uma regra que limita a três operações de crédito com subvenções para cada cliente, mas não há um controle para as operações prévias, tampouco um cruzamento de operações de crédito entre diferentes organizações, o que reduz a capacidade de controle de sobre-endividamento dos tomadores de crédito. 


\section{Scmepp-Empresta Capital}

\section{Dimensão contexto}

Diante de negociações fragilizadas com o governo e uma regulamentação muito rígida, as Scmepps dependem muito de inovações próprias para obter bons resultados, como é o caso da Empresta Capital. A criação de um Fundo de Investimento em Direitos Creditórios (FIDC), assim como o foco e especialização em um segmento específico, foi uma inovação particular dessa organização para gerar resultados em seus negócios.

No contexto geral, o diretor da Empresta Capital afirma que o modelo jurídico de Scmepp ainda não é um bom negócio. Isso se deve à impossibilidade de captação de recursos de acordo com a regulamentação do Banco Central. Além disso, a regulamentação das Scmepps é muito rígida e, de acordo com o entrevistado, esse é um dos principais fatores que explicam a diminuição do número dessas organizações no País. "E a gente vê que o modelo é tão travado que dificulta muita coisa. Então, mata um pouco o que é ser o microcrédito, o que é ser uma empresa de microcrédito" (entrevista com o diretor da Empresta Capital, 23 de agosto de 2013).

Segundo o diretor da Empresta Capital, a empresa só é um bom negócio devido à criação de um modelo de fundo de captação de recursos. Antes, a Empresta tinha crédito, mas caía no mesmo segmento das chamadas factorings. Esse fundo é aberto e é o único fundo de microcrédito no Brasil, mas não tem nenhuma regulação específica sendo um modelo de FIDC como todos os outros. "A gente é um case nesse segmento. Quando você fala no FIDC pequeno, o nos- so é 15 vezes menor" (entrevista com diretor da Empresta Capital, 23 de agosto de 2013). O diretor da Empresta Capital relatou que a estrutura da SCM é baseada no equilíbrio da equação de volume, segurança e simplicidade. Volume de clientes, segurança de retorno dos empréstimos, e acesso simples e fácil ao cliente. Outro fator determinante para a Empresta ser um bom negócio é sua estratégia de trabalho voltada para a especialização e o foco em segmentos específicos. De acordo com o diretor da Empresta Capital, a raiz das pessoas na comunidade é fundamental para garantir a confiabilidade, pois, quando as pessoas têm família e história na comunidade, cria-se uma questão moral entre as pessoas do local. Nesse sentido, a Empresta Capital analisou a raiz das pessoas em seus locais de moradia e selecionou focar seu trabalho em comunidades específicas.

O entrevistado acredita que as principais características do microcrédito, quando comparado ao crédito tradicional, são a especificidade da linguagem e a informalidade do segmento. Para tanto, o conhecimento da linguagem do cliente viabiliza o contato e o acesso ao segmento do microcrédito, que é muito diferente do ambiente formal de um banco tradicional.

Atualmente, o principal desafio das Scmepps é a captação de recursos. Mas, de acordo com o diretor da Empresta Capital, o potencial de mercado do microcrédito é muito vasto, "cliente não é problema, potencial de mercado não é problema". E não há competidores, pois os bancos e financeiras, que seriam os competidores mais fortes, não têm tentáculos para chegar ao público de microcrédito. "É muito difícil, não é interessante para eles, assim como não é interessante 
para mim dar um crédito para a Vale do Rio Doce. É a mesma coisa" (entrevista com diretor da Empresta Capital, 23 de agosto de 2013).

\section{Dimensão processo}

A atuação das Scmepps depende, em grande medida, das normas e regulamentos definidos pelo Banco Central, que, por sua vez, envolve processos de consulta e negociação dentro do próprio segmento. $O$ entrevistado acredita que o mercado das Scmepps começou em 2008 com a alteração e flexibilização no acesso ao crédito pelo Banco Central. Essa mudança foi uma proposta que surgiu na mediação entre o Banco Central e a Associação Brasileira das Sociedades de Crédito ao Microempreendedor (ABSCM), contando com a participação da Empresta Capital. Nessa negociação, muitas propostas foram feitas, e algumas delas foram acatadas pelo Banco Central.

A Empresta Capital busca iniciar parcerias no nível meso, como a parceria com a Fundação Getulio Vargas, que oferece oportunidades para empreendedores realizarem cursos de pós-graduação. Além disso, a SCMEPP também está tentando uma parceira com o Sebrae para oferecer cursos de formalização.

No que tange à representação das Scmepps, a ABSCM é a principal representante do segmento, mas, segundo o entrevistado, essas associações têm pouca participação no processo decisório e na formulação de políticas públicas de microcrédito, apesar de ser uma reivindicação delas.

O diretor da Empresta Capital acredita que o governo ainda é pouco aberto à participação e conhece pouco do setor de microcrédito, e afirma que: "O governo poderia ser mais ativo e chegar na ponta, $E$ perguntar para os atores mesmo o que é real, o que não é. Basicamente, eu diria que o governo não conhece o microcrédito no Brasil. Ele é uma coisa muito mais populista, eleitoreira".

\section{Dimensão conteúdo}

Atualmente, a Empresta Capital tem cerca de cinco mil clientes ativos, o ticket médio é de $R \$ 3.700,00$ e $35 \%$ da carteira é voltada para gerar lastro para o fundo anteriormente mencionado. A perda efetiva nas operações de crédito gira em torno de $5 \%$. Os principais resultados da Empresta Capital devem-se à sua inovação em criar um fundo de investimentos para o microcrédito, o que reduz custos de transação e custos tributários, e a atenção contínua dada à administração de risco. Além disso, o processo de negociação com o Banco Central impacta diretamente os resultados, na medida em que os custos regulatórios, relacionados ao atendimento às exigências do Banco Central, são elevados.

A flexibilização da regulamentação de acesso ao crédito pelas Scmepps, em 2008, surgiu a partir da proposta e negociação da ABSCM com o Banco Central. Portanto, a associação e negociação entre as Scmepps, por meio da ABSCM e o Banco Central, é fundamental para criar um ambiente adequado de atuação nesse mercado. Todavia, o representante da Empresta Capital afirma que ainda é necessário haver mais flexibilização nas regulamentações e mais participação e proximidade com outros órgãos governamentais. 


\section{Oscip - Banco Pérola}

\section{Dimensão contexto}

O Banco Pérola, criado em 2010, surgiu por meio da experiência da fundadora do banco como aluna e coordenadora do Projeto Pérola, iniciativa de inclusão digital da cidade de Sorocaba. A ideia de criar o Banco Pérola surgiu por meio de uma das iniciativas do Projeto Pérola - a "Escola de Talentos", que tinha como objetivo ensinar jovens empreendedores de baixa renda a fazer um plano de negócio. Com a experiência desse projeto, a coordenadora criou o Banco Pérola, que tem o objetivo de conceder microcrédito aos empreendedores da comunidade Ana Paula e Altério, mais conhecido como Habiteto.

A forma jurídica do Banco Pérola é Oscip Creditícia, e seu principal produto é o MPO. "E a gente segue à risca o Microcrédito Produtivo e Orientado", afirma a fundadora do banco. O banco faz visitas, atendimentos e consultoria, e seu principal diferencial é auxiliar os empreendedores a construírem seus planos de negócios e investirem em negócios que ainda estão começando, startups. Além disso, se o empreendedor ainda não se sente seguro para iniciar seu negócio, o banco promove um intercâmbio de experiência com outro negócio que já está em andamento. Segundo a entrevistada, $48 \%$ dos negócios apoiados pelo banco começam a partir do plano de negócios, e $70 \%$ dos negócios apoiados começam com menos de seis meses.

Durante entrevista com a coordenadora e o analista jurídico do Banco Pérola, os entrevistados afirmaram que há casos em que o empreendedor solicita apenas o serviço de consultoria do banco e não solicita crédito. Ademais, há casos em que o empreendedor já está preparado para ter crédito de bancos tradicionais, mas prefere continuar no Banco Pérola devido ao acompanhamento e consultoria que ele oferece. Segundo a fundadora do banco, a essência de seu trabalho é o acompanhamento e o relacionamento com os empreendedores. De acordo com suas palavras: "O dinheiro acaba fazendo parte, é a cereja do bolo, mas não é o principal".

\begin{abstract}
Esse caráter de consultoria, o orientado, é o mais forte do nosso processo. [...] Então, eles costumam ver as pessoas da equipe como consultores, o crédito ele faz parte, mas na "Escola de Talentos", que foi a ideia inicial, ainda é muito presente dentro do nosso processo. É fundamental, porque isso mantém inadimplência baixa, isso mantém índice de sucesso alto. (entrevista com diretora do Banco Pérola, 23 de setembro de 2013)
\end{abstract}

Neste momento, os principais desafios do banco estão relacionados à implementação de um fundo nos moldes da Empresta Capital e a transformação institucional de Oscip, sem finalidade de lucro, para um modelo de Scmepp, com finalidade de lucro. Um dos desafios é manter qualidade e estrutura para atender um maior número de pessoas.

\section{Dimensão processo}

O órgão responsável pelo acompanhamento e fiscalização das Oscips Creditícias é o Ministério da Justiça. No entanto, os entrevistados do Banco Pérola afirmaram que nunca tiveram contato com o Ministério. Diante do objetivo de se transformar em uma empresa 


\section{MICROCRÉdITO PRODUTIVO NO BRASIL: HISTÓRICO RECENTE E CONDICIONANTES DE DESENVOLVIMENTO}

uma Scmepp, o Pérola entrou em contato com o Banco Central, que deu assistência in loco durante uma semana. Após essa aproximação, os entrevistados afirmaram ter aprendido muito, apesar de terem tomado a decisão de não se tornar Scmepp nesse momento, pois o Banco Central aconseIhou-os a esperar, devido às transformações que estão ocorrendo nesse setor. De acordo com a fundadora do Banco Pérola:

Hoje a gente está com um sistema que gera os relatórios que uma Scmepp deveria gerar. A gente está com um processo dossier todo de acordo com o que o Banco Central exige. Então toda a nossa gestão está baseada no Banco Central, apesar de a gente não ser regulamentado. [...] Então, o lado bom de tudo isso é que profissionalizou muito nosso trabalho, esse intercâmbio que a gente fez com eles. (entrevista com a diretora do Banco Pérola, 23 de setembro de 2013)

De acordo com a diretora do Pérola, existem algumas vantagens em tornar-se Scmepp, como o repasse de verba de bancos tradicionais que ocorre com mais facilidade ou, ainda, uma melhor comunicação com bancos tradicionais. Todavia, permanece o desafio de captação de depósitos do público. "Então, uma [Scmepp] resolve a questão operacional, de relacionamento com os bancos. A outra [Oscip] resolve a questão social, mas nenhuma resolve a outra parte do negócio, que é ter um fluxo recorrente de recurso" (entrevista com diretora do Banco Pérola, setembro de 2013).

Com o objetivo de superar o desafio da captação de recursos, o Banco Pérola vai implantar um FIDC, que será viabilizado por conta das parceiras da Oscip com bancos e investidores, e trará mais captação de recursos.

No que diz respeito às inter-relações do Banco Pérola, no nível micro, há parcerias com bancos privados e com a instituição financeira Sorocred, com a qual contraiu empréstimos. Ainda no nível micro, há parcerias com o Banco Bradesco e a Caixa Econômica. O Pérola tem um limite de crédito aprovado na Caixa Econômica e no Banco Bradesco, mas esse limite não é utilizado, por ser caro e muito burocrático. Portanto, o contato do Banco Pérola com essas duas instituições é voltado para a troca de aprendizagem e de metodologia de trabalho.

No nível meso, que se refere ao auxílio de instituições de apoio e assistência, o Banco Pérola contou com o apoio do Sebrae Nacional, mas apenas para a construção de seu plano de negócios, no início de sua atuação. Segundo a entrevistada, "até hoje a gente usa muitas informações boas de negócios que eles ajudaram a gente a construir."

No nível macro, os entrevistados do Banco Pérola afirmaram que o governo é pouco atuante e está muito focado nos interesses particulares. Os representantes do Banco Pérola não participam de conselhos ou outras instituições representativas do governo, mas participam das assembleias da $A B-$ CRED, e acham que sua atuação poderia ser mais efetiva. Já o Banco Central é visto como uma instituição diferenciada no setor público, conforme pode ser observado no seguinte depoimento:

Eu tinha uma visão antes, e uma visão depois, do Banco Central. Antes, eu colocava 
no mesmo pacote, do poder público. Mas depois que eu conheci eu vi que tem muita gente boa lá. Muita gente que quer fazer efetivamente. (entrevista com diretora do Banco Pérola, 23 de setembro de 2013)

De acordo com os entrevistados do Banco Pérola, a regulamentação estabelecida pelo Banco Central é muito positiva, pois ela oferece ferramentas de trabalho mais profissionais e mais transparência, proporcionando segurança e proteção às instituições, e maior confiança aos investidores.

\section{Dimensão conteúdo}

No primeiro ano de atuação do Banco Pérola, foram atendidos 28 empreendedores, e atualmente o banco tem cerca de 130 clientes ativos na carteira, mas existe um total de 400 clientes que mantém vínculo com o banco para fins de consultoria e assistência. Desde o início de sua atuação, o banco já atendeu 600 empreendimentos.

O crédito médio de seus clientes é de cerca de três mil reais por ano. Hoje a Oscip tem 412 mil reais de recursos disponíveis, não necessariamente em crédito ativo, pois parte é usada para investimento em equipe, tecnologia, metodologia e gestão. A taxa média de inadimplência do Banco Pérola é de 2,1 , calculada com base na Resolução $n$. 2.682 do Banco Central.

A Oscip analisada está crescendo gradualmente em seu mercado de atuação, e há uma preocupação em conciliar crescimento e qualidade do serviço. O grande número de empreendedores que utilizam o serviço de consultoria da Oscip revela a qualidade de assessoria prestada, assim como o baixo ní- vel de inadimplência também é uma consequência da proximidade e orientação ao crédito para os empreendedores. Os resultados obtidos devem-se, em grande medida, ao seguimento rígido da metodologia do MPO e ao esforço no aperfeiçoamento de sua gestão, que teve um grande avanço a partir da aproximação com o Banco Central.

Análise comparativa entre as três instituições As três organizações analisadas apresentam sucesso em seus resultados no que diz respeito à baixa taxa de inadimplência e crescimento no número de clientes. Porém, esses resultados devem-se a contextos e estratégias diferentes.

No nível da gestão, dimensão contexto, todas as organizações investem na metodologia do MPO, sobretudo no acompanhamento e consultoria ao cliente e ao crédito em grupo. Das três organizações, aquela que tem maior destaque na consultoria dos negócios de seus clientes é o Banco Pérola, sendo também a única que investe em negócios recém iniciados. O Banco do Nordeste adota como estratégia de gestão a desburocratização e o foco em resultados. O principal destaque da gestão da Scmepp Empresta Capital é a criação de um FIDC específico para o microcrédito e o foco em clientes de uma única região. Já o Banco Pérola tem investido no modelo de gestão sugerido pelo Banco Central, que segue as diretrizes de uma Scmepp.

Diante dos obstáculos ao microcrédito ressaltados por Aghion e Morduch (2010), o Banco Pérola tem um maior conhecimento sobre os negócios e o comportamento de seus clientes, mitigando o problema da assimetria de informação. Entretanto, para o Banco Perola 
e Oscips em geral, é fundamental ganhar escala, sob pena de incorrer em custos de transação insustentáveis (Morduch, 1999). Ademais, os modelos jurídicos impostos pela legislação brasileira não autorizam Oscips e Scmepps a captarem depósitos, o que enfraquece sua posição competitiva perante os bancos públicos, reforçando a presença do governo no microcrédito, como descrito por Monzoni (2006). Isso ajuda a explicar a preponderância do Banco do Nordeste no microcrédito. O FIDC (Fundo de Investimento em Direitos Creditórios) criado pela Empresta Capital, devido à finalidade especificamente voltada para o microcrédito, representa um inovação capaz de reduzir os custos de transação associados à captação de recursos, além de utilizar um mecanismo de mercado, a estruturação de fundos, que pode ter efeitos positivos para a imagem da Scmepp. Trata-se de uma combinação de inovações, como sugerido por Gonzalez et al. (2009). Na dimensão processo, conforme ressaltado, aquele que tem maior poder de influência política e articulações com órgãos governamentais é o banco público. Olsen (2013), em estudo comparado entre as microfinanças no Brasil e no México, ressalta a diferença entre ação coletiva e influência coletiva, sendo a última justamente aquela pouco alcançada pelas Oscips e Scmpepps no Brasil, que não lograram obter o tipo de regulação desejado. $O$ exemplo mais óbvio é o fato de ser vedado a essas organizações capturar depósitos do público em geral.

Portanto, Empresta Capital e Banco Pérola têm baixo poder de influência política e articulação com políticas públicas (nível macro), apesar de contarem com organizações representativas de seus respectivos segmentos, como a ABSCM e ABCRED (nível meso). No caso do Pérola e das Oscips, sua articulação governamental é ainda mais fragilizada, pois não há nenhum contato ou assessoria por parte do Ministério da Justiça, órgão regulador das Oscips. Interessante que a gestão do Banco Pérola foi aprimorada a partir do contato com o Banco Central, órgão regulador das Scmepps, e não das Oscips.

No nível meso, as condições também são menos favoráveis para a Oscip. Enquanto o Banco do Nordeste é favorecido pelas parcerias com ONGs locais, que podem facilitar o maior contato com as comunidades, a Scmepp tem maior facilidade de realizar transações com parceiros e bancos privados. Como forma de compensação, o Banco Pérola busca valer-se da maior proximidade por meio dos agentes de crédito, o que tende a gerar menor inadimplência esperada (Quayes, 2012).

Em suma, a avaliação das dimensões contexto, processo e conteúdo do Banco do Nordeste, da Empresta Capital e do Banco Pérola demonstram que os resultados positivos das diferentes instituições devem-se a premissas diferentes. No caso do Banco do Nordeste, há uma associação entre estratégias internas de gestão, ambiente jurídico favorável e forte poder de influência política, no nível macro do sistema de microcrédito. Já a Empresta Capital e o Banco Pérola atuam em um ambiente jurídico desfavorável e têm pouco poder de influência política, assim como poucas parcerias com órgãos governamentais. Portanto, essas organizações devem seus resultados às suas estratégias de gestão, não obstante os desafios para alavancar o crescimento. 
Quadro 1. Resumo da análise

\begin{tabular}{|c|c|c|c|}
\hline & Dimensão contexto & Dimensão processo & Dimensão conteúdo \\
\hline $\begin{array}{l}\text { Banco do } \\
\text { Nordeste }\end{array}$ & $\begin{array}{l}\text { 1. Gestão voltada para } \\
\text { resultados e desburocra- } \\
\text { tização do banco; } 2 \text {. In- } \\
\text { vestimento na aplicação } \\
\text { da metodologia do MPO; } \\
\text { 3.Acesso a recursos de } \\
\text { governo. }\end{array}$ & $\begin{array}{l}\text { 1. Parcerias com Oscips } \\
\text { para operacionalização } \\
\text { da oferta do microcrédito; } \\
\text { 2. Articulação e parceria } \\
\text { com políticas públicas para } \\
\text { implementação do Credia- } \\
\text { migo e Agroamigo; 3. Forte } \\
\text { poder político nos proces- } \\
\text { sos decisórios de diversos } \\
\text { órgãos governamentais. }\end{array}$ & $\begin{array}{l}\text { 1. Baixa taxa de inadimplência; } \\
\text { 2. Crescimento do número de } \\
\text { clientes; 3. Eficiência do serviço } \\
\text { deve-se às estratégias de ges- } \\
\text { tão e parcerias com o governo. }\end{array}$ \\
\hline $\begin{array}{l}\text { Empresta } \\
\text { Capital }\end{array}$ & $\begin{array}{l}\text { 1. Inovação por meio da } \\
\text { criação de um FIDC es- } \\
\text { pecífico para o microcré- } \\
\text { dito; } 2 \text {. Investimento na } \\
\text { aplicação da metodologia } \\
\text { do MPO; 3. Foco e es- } \\
\text { pecialização em um seg- } \\
\text { mento/público específico; } \\
\text { 3. Regulamentação muito } \\
\text { rígida para a atuação das } \\
\text { Scmepps; } 4 \text {. Dificuldade } \\
\text { de captação de recursos. }\end{array}$ & $\begin{array}{l}\text { 1. As negociações com o } \\
\text { governo são fragilizadas, } \\
\text { apesar de já terem ocor- } \\
\text { rido mudanças na regula- } \\
\text { mentação do BC para as } \\
\text { Scmepps, devido à pres- } \\
\text { são política da ABSCM; } 2 \text {. } \\
\text { Falta de articulação com o } \\
\text { governo para as políticas } \\
\text { públicas no segmento das } \\
\text { Scmepps. }\end{array}$ & $\begin{array}{l}\text { 1. Baixa taxa de inadimplência; } \\
\text { 2. Crescimento do número de } \\
\text { clientes; 3. Eficiência do serviço } \\
\text { deve-se às estratégias internas } \\
\text { de gestão e ao FIDC; } 4 \text {. A rigi- } \\
\text { dez da regulamentação e falta } \\
\text { de articulação das Scmepps } \\
\text { com as políticas públicas preju- } \\
\text { dica seus resultados. }\end{array}$ \\
\hline $\begin{array}{l}\text { Banco } \\
\text { Pérola }\end{array}$ & $\begin{array}{l}\text { 1.Atuação relevante em } \\
\text { consultoria, que muitos } \\
\text { clientes utilizam exclusi- } \\
\text { vamente, ou sem recorrer } \\
\text { ao microcrédito; } 2 \text {. Ino- } \\
\text { vação pela atuação em } \\
\text { startups; 3. Apesar de ser } \\
\text { uma Oscip, implementa } \\
\text { todos os procedimentos } \\
\text { de gestão exigidos pela } \\
\text { regulamentação de Sc- } \\
\text { mepp. }\end{array}$ & $\begin{array}{l}\text { 1. A Oscip nunca teve con- } \\
\text { tato com o Ministério da } \\
\text { Justiça, órgão fiscalizador } \\
\text { das Oscips de microcrédi- } \\
\text { to, mas teve muito contato } \\
\text { com o Banco Central, ao } \\
\text { planejar transformar-se } \\
\text { em Scmepp; 2. Possui } \\
\text { parceria com o Banco Bra- } \\
\text { desco, Caixa Econômica e } \\
\text { a Sorocred; 3. Participa de } \\
\text { reuniões da ABCRED; } 4 . \\
\text { Não participa das decisões } \\
\text { governamentais da área e } \\
\text { não tem parcerias com po- } \\
\text { líticas públicas. }\end{array}$ & $\begin{array}{l}\text { 1. Baixa taxa de inadimplência; } \\
\text { 2. Crescimento do número de } \\
\text { clientes; 3. Melhora das estraté- } \\
\text { gias de gestão após a aproxima- } \\
\text { ção com o Banco Central. }\end{array}$ \\
\hline
\end{tabular}




\section{CONCLUSÃO}

O estudo dos modelos institucionais de microcrédito - banco público, Scmepp e Oscip - revelou que os resultados de sucesso dependem da combinação de estratégias internas e variáveis externas. As estratégias internas dizem respeito à gestão da organização, capacidade de inovação e foco na aplicação da metodologia do MPO. As estratégias externas dizem respeito ao fortalecimento das associações de representação como a ABSCM e ABCRED, e negociações com órgãos governamentais.

O banco público é aquele com maiores vantagens organizacionais, pois conta com condições favoráveis para a captação de recursos, forte articulação com políticas públicas e forte poder de influência no processo decisório do governo e das regulamentações do microcrédito. Suas vantagens nos processos de negociação são determinantes para os resultados na oferta de microcrédito.

Já as Scmepps e Oscips apresentam grandes dificuldades de atuação devido ao modelo jurídico e regulatório de suas instituições. Esses modelos as impedem de captar recursos junto ao público e tendem a comprometer a captação de recursos no mercado. Além disso, ambas as organizações possuem baixo poder de influência e articulação com os órgãos governamentais para tornar suas regulamentações jurídicas mais favoráveis à atuação no segmento do microcrédito. Portanto, seus resultados positivos devem-se às estratégias internas de gestão, e seus desafios são marcados pelas restrições normativas de expansão para a oferta de crédito.
O Banco Central merece destaque na sua capacidade de assessorar as instituições de microcrédito. Mesmo a Oscip Banco Pérola, que é supervisionada pelo Ministério da Justiça, revelou grande avanço na sua gestão quando teve a oportunidade de se aproximar do Banco Central. No entanto, com exceção do Banco do Nordeste, a participação no processo decisório das políticas públicas de microcrédito com os ministérios é bastante frágil e quase inexistente nos casos da Scmepp e da Oscip.

A análise mostra que as condicionantes para o futuro do microcrédito indicam dificuldades para atuação de organizações que não sejam públicas, caso não haja alteração no ambiente regulatório das Oscips e Scmepps. Nesse contexto, o papel da ABCRED e da ABSCM pode ser funcional para mediar as relações com órgãos governamentais $\mathrm{e}$ pautar reformas institucionais que favoreçam a ação das Scemepps e das Oscips.

\section{REFERÊNCIAS}

Aghion, B. A., \& Morduch, J. (2010). The economics of microfinance. Massachusetts, EUA: The MIT Press.

Al-Azzam, A. R. M., Carter, H., \& Sudipta, S. (2012). Repayment performance in group lending: Evidence from Jordan. Journal of Development Economics, (972), 404-414. doi:10.1016/j.jdeveco.2011.06.006

Banco do Nordeste. (2016). Resultados. Recuperado de https://www.bnb.gov.br/resultados

Cacciamali, M. C., Matos, F., \& Macambira, J. (2014). O setor de microfinanças e as 
políticas de microcrédito no Brasil. In F. de Matos, J. Macambira, \& M. C. Cacciamali (Orgs.), A atividade e a política de microcrédito no Brasil: Visões sobre sua evolução e futuros desafios (pp. 17-34). Fortaleza, CE: IDT/USP.

Cernev, A. (2010). Mobile banking no Brasil: Eventos críticos, trajetória e cenários esperados (Tese de doutorado em Administração de Empresas, FGV, São Paulo, SP).

Diniz, E. H., Pozzebon, M., \& Jayo, M. (2009). The role of ICT in helping parallel paths to converge: Microcredit and correspondent banking in Brazil. Journal of Global Information Technology Management, 12, 80-103.

Gonzalez, L., Piza, C., \& Garcia, D. (2009). Sinergia entre microsseguro e microcrédito e o crescimento dos mercados no Brasil. Revista Brasileira de Risco e Seguro, 5(10), 45-84.

Gonzalez, L., Diniz, E., \& Pozzebon, M. (2015). The value of proximity finance: How the traditional banking system can contribute to microfinance. Innovations, 10(1-2), 125137. doi:10.1162/inov_a_00233

Global Entrepreneurship Monitor (2014). Global Report. Recuperado de https://www. sebrae.com.br/Sebrae/Portal\%20Sebrae/ Estudos $\% 20$ e $\% 20$ Pesquisas/gem $\% 20$ 2014_relat\%C3\%B3rio\%20executivo.pdf

Helms, B. (2006). Access for all: Building inclusive financial systems. Washington, USA: World Bank. World Bank.

Instituto de Pesquisa Econômica Aplicada (2010). O BNB Como Banco de Desenvol- vimento e Banco de Crédito Agrícola: Desempenho, Mudanças, Desafios. Recuperado de: http://www.ipea.gov.br/ppp/index.php/ PPP/article/view/169

Jayo, M. (2010). Correspondentes bancários como canal de distribuição de serviços financeiros: Taxonomia, histórico, limites e potencialidades dos modelos de gestão de redes (Tese de doutorado em Administração de Empresas, FGV, São Paulo, SP).

Khavul, S. (2010). Microfinance: Creating opportunities for the poor? Academy of Management Perspectives, 24(3), 58-72.

Lavoie, F., Pozzebon, M., \& Gonzalez, L. (2011). Challenges for inclusive finance expansion: The case of CrediAmigo, a Brazilian MFI. Management International, 15(3), 57-69. doi:10.7202/1005433ar

Monzoni, M. P., Neto. (2006). Impacto em renda do microcrédito: Uma investigação empírica sobre geração de renda do crédito popular solidário (São Paulo Confia), no município de São Paulo (Tese de doutorado em Administração Pública e Governo, FGV, São Paulo, SP).

Morduch, J. (1999, December). The microfinance promise. Journal of Economic Literature, 37(4), 1569-1614.

Neri, M. C., \& Giovanini, F. D. S. (2005). Negócios nanicos, garantias e acesso a crédito. Revista de Economia Contemporânea, 9(3), 643-669.

Olsen, T. (2013). Rethinking collective action: The case of microfinance in Brazil and Mexi$c o$. Working paper prepared for the Sié Rese- 
arch Seminar Series Joseph Korbel School of International Studies, University of Denver, USA.

Pozzebon, M., Diniz, E., \& Jayo, M. (2008). Adapting the structurationist view of technology for studies at the community/societal levels. In Dwevedi, Y. Lal, B. Williams, M.D. Schneberger, S.L. Wade, M.R (Eds.), Handbook of research on contemporary theoretical models in information systems (pp. 18-33). Hershey/London, UK: Information Science Reference.

Quayes, S. (2012). Depth of outreach and financial sustainability of microfinance institutions. Journal of Applied Economics, 44(26), 3421-3433. doi:10.1080/00036846. 2011.577016

Roodman, D., \& Morduch, J. (2014). The impact of microcredit on the poor in Bangladesh: Revisiting the evidence. Journal of De- velopment Studies, 50(4), 583-604. doi:10.1 080/00220388.2013.858122

Wolf, M (2007). Unfettered finance is fast reshaping the global economy. Financial Times. Recuperado de https://www. ft.com/content/518482b4-1dc5-11dc-89f7000b5df10621

Yin, R. K. (2001). Estudo de caso: Planejamento e métodos. Porto Alegre, RS: Bookman.

Zouain, D. M., \& Barone, F. M. (2007). Excertos sobre política pública de acesso ao crédito como ferramenta de combate à pobreza e inclusão social: O microcrédito na era FHC. RAP-Revista de Administração Pública, 41(2), 369-380. doi:10.1590/S003476122007000200010 